Silvia Piedade de Moraes ${ }^{1}$

Maria Sylvia de Souza Vitalle ${ }^{1}$

${ }^{1}$ Setor de Medicina do Adolescente, Departamento de Pediatria, Universidade Federal de São Paulo. R. Botucatu 715, Vila Clementino. 04023-062 São Paulo SP Brasil. silviapmoraes@hotmail.com

\title{
Direitos sexuais e reprodutivos na adolescência: interações ONU-Brasil
}

\author{
Sexual and reproductive rights during adolescence: \\ UN-Brazil interactions
}

\begin{abstract}
The scope of this article is to describe the international documents of the UN and laws passed in Brazil from 1950 onwards focusing on sexual and reproductive rights during adolescence. It involved a descriptive study by consulting the official website of the UN organ entitled the Economic Commission for Latin America and the Caribbean and sites of the President of the Republic, Ministry of Health and Education and the Virtual Health Library. The documents were organized from 1950 to 2010 with an emphasis on sexual and reproductive rights and adolescence. Ten conferences were found within the scope of the UN: six conferences on Population and Development, two on Human Rights, one on the Rights of the Child and another on the Millennium Development Goals. Thirty-two documents were found in the field of national legislation (four decrees, thirteen federal laws, three technical norms, two ordinances, three resolutions, a technical note and six programs). The role of the UN and Brazil in consolidating the broad concept of sexual and reproductive rights has made significant progress, however greater achievements in the area of reproductive rights still prevail.
\end{abstract}

Key words Adolescent, Sexuality, Legislation as a topic, Advocacy of children and adolescents, United Nations
Resumo O objetivo deste artigo é descrever os documentos internacionais da ONU e as legislações produzidas no Brasil a partir de 1950 com foco nos direitos sexuais e reprodutivos na adolescência. Estudo descritivo com consulta ao site oficial da Comisión Económica para América Latina y el Caribe, órgão das Nações Unidas e em sites da Presidência da República, Ministério da Saúde e Educação e na Biblioteca Virtual em Saúde. Os documentos foram organizados de 1950 a 2010 com recorte sobre direitos sexuais e reprodutivos e a adolescência. No âmbito da ONU encontraram-se dez conferências: seis sobre População e Desenvolvimento, duas sobre Direitos Humanos, uma Convenção dos Direitos da Criança e as Metas do Milênio. No campo da legislação nacional encontraram-se trinta e dois documentos (quatro decretos, treze leis federais, três normas técnicas, duas portarias, três resoluções, uma nota técnica e seis programas). A atuação da ONU e do Brasil em consolidar um conceito amplo de direitos sexuais e reprodutivos obteve avanços significativos, no entanto, ainda prevalecem maiores conquistas na área dos direitos reprodutivos.

Palavras-chave Adolescente, Sexualidade, Legislação como assunto, Defesa da criança e do adolescente, Nações Unidas 


\section{Introdução}

Mesmo sendo antiga a ideia de que os seres humanos têm direitos inalienáveis foi somente após a segunda metade do século XX que os mesmos passaram a ser reafirmados internacionalmente ${ }^{1}$. Na década de 1940 a ONU (Organização das Nações Unidas) realizou diversas conferências em que a relação entre demografia, desenvolvimento e direitos sexuais e reprodutivos estiveram presentes $^{2}$. Essas conferências demonstraram a preocupação com o binômio população e desenvolvimento e importantes debates foram estabelecidos sobre as barreiras adequadas ao crescimento populacional ${ }^{2,3}$.

No entanto, a atuação da ONU e seus organismos não têmsido vista de forma positiva por todos os Estados-parte. Se por um lado alguns fortalecem e apoiam os ideários considerando-os como uma renovação da consciência histórica sobre a humanidade, outros questionam a legitimidade e a capacidade de exigir dos Estados-parte uma atuação plena ${ }^{1}$.

A ONU teve ao longo de sua atuação muitas discussões sobre saúde sexual e reprodutiva, no início com uma política um tanto controladora e mais tarde (e ainda alcançando) uma abordagem em direitos ${ }^{4-6}$. Outro ponto importante é o envolvimento de jovens e adolescentes nos problemas sociais, econômicos e culturais. Vistos como a próxima geração, entende-se que devam desenvolver seu potencial para aprender a manter-se saudável, planejar e criar seus filhos e estarem mais protegidos das altas taxas de mortalidade materna e morbidade, abortos inseguros, altos índices de doenças sexualmente transmissíveis e filhos abandonados como aponta o cenário mundial ${ }^{7,8}$.

Nosso ponto de vista pauta-se na percepção de que com todas as limitações (já que a internacionalização das políticas tem aspectos ideológicos jurídicos, culturais e religiosos e econômicos muitas vezes bem distintos e, por isso, a diplomacia é um dos aspectos mais importantes) os organismos internacionais podem ter uma atuação bem sucedida na criação de parâmetros de ação e organização de políticas públicas ${ }^{1}$.

No caso do Brasil há deficiência no que tange a implementação das legislações estabelecidas, necessitando maior conhecimento dos profissionais que atuam no segmento e nas resoluções de conflitos éticos da prática legal de tais ações ${ }^{9}$. Mesmo com algumas políticas neste setor, no Brasil o nível de informação dos adolescentes sobre sua sexualidade ainda é pequeno, sobretudo entre as meninas ${ }^{10} \mathrm{o}$ que aumenta a vulnerabilidade $^{9,11}$.

Destacamos a palavra "interação" no título deste artigo porque não houve de fato uma influência verticalizada da ONU sobre o Brasil, mas discussões semelhantes num mesmo espaço de tempo. As produções de um e de outro são processo e produto num movimento saudável de influências.

O objetivo deste artigo é discutir a interação dos documentos internacionais da ONU com as legislações produzidas no Brasil a partir de 1950. A descrição dos documentos e leis focou apenas os direitos sexuais e reprodutivos na adolescência e acompanharam a trajetória conceitual, histórica e de ampliação de direitos em sessenta anos na ONU e no Brasil.

\section{Método}

Dada a escassez de artigos publicados contemplando a articulação dos marcos internacionais com a legislação brasileira, foi realizado estudo descritivo, analítico, sem fatores de comparação que seguiu as seguintes etapas de levantamento, seleção e análise:

1. A pesquisa baseou-se em consulta ao site oficial da Comisión Económica para América Latina y el Caribe ${ }^{12}$, órgão das Nações Unidas na área de conferências.

2. O levantamento das legislações nacionais foi realizado em sites oficiais da Presidência da República, do Ministério da Saúde e Educação e na Biblioteca Virtual em Saúde.

3. Todos os documentos e leis foram organizados em décadas, partindo de 1950 até 2010.

4. Através de leitura criteriosa realizou-se o recorte sobre direitos sexuais e reprodutivos associados à faixa etária da adolescência.

5. Foram excluídos os documentos em que não foi possível acessar os relatórios e planos de ação na íntegra.

\section{Resultados e discussão}

No âmbito da $\mathrm{ONU}^{12}$ encontraram-se dez conferências, sendo que seis foram sobre População e Desenvolvimento (Roma -1954; Belgrado - 1965; Bucareste - 1974; México - 1984; Cairo - 1994; Cairo+5 - 1999) e duas de Direitos Humanos (Teerã - 1968; Viena - 1993), uma sobre Convenção dos Direitos da Criança (1990) e as Metas do Milênio (2000), proposta de atuação transversal 
da ONU sobre questões urgentes. Foram excluídos dois documentos (Roma-1954 e Belgrado-1965) devido a inacessibilidade aos relatórios e planos de ação.

No campo da legislação nacional encontraram-se trinta e dois documentos de valor legal (quatro decretos, treze leis federais, três normas técnicas, duas portarias, três resoluções, uma nota técnica e seis programas) para todo o território brasileiro.

As conferências da ONU foram paulatinamente ganhando conotação mais política e estabelecendo diretrizes aos países, elucidando as bases e a ampliação gradativa de direitos à saúde sexual e reprodutiva ${ }^{5}$. O Brasil acompanhou a ampliação dos acordos fortalecendo as conquistas na legislação nacional.

Neste contexto, a ONU tenta introduzir um paradigma articulando as relações entre população, desenvolvimento e direitos, e sexualidade com democracia. A figura do adolescente foi aos poucos sendo introduzida nos documentos como um segmento importante.

Na sequência deste artigo usaremos os termos "direitos reprodutivos e saúde sexual" e "direitos sexuais e reprodutivos", visto que em alguns momentos os documentos e as legislações se aproximam politicamente do segundo, embora os direitos sexuais ainda não tenham sido validado de fato pela ONU.

\section{As décadas de 1950 a 1969}

- a invisibilidade da adolescência

Com o objetivo de referendar, fortalecer e examinar os progressos advindos dos vinte anos após a Declaração Universal de Direitos Humanos, a Conferência Mundial de Direitos Humanos-Teerã, 1968, foi um reforço que visou garantir bem-estar físico, mental e social e espiritual aos seres humanos ${ }^{13}$. Seu marco foi colocar no campo dos direitos humanos as liberdades fundamentais, a igualdade em direitos para mulheres e homens, o direito de indivíduos decidirem livremente sobre a reprodução e a importância dos jovens nas mudanças do futuro da humanidade $^{6,14,15}$.

Recomendou-se também o incentivo à participação dos jovens nas aspirações de um mundo melhor, destacando a visão preliminar de protagonismo juvenil, que mais tarde será inserido como ação fundamental nas políticas de direitos sexuais e reprodutivos ${ }^{13}$.

No Brasil, as taxas de fecundidade diminuíram impulsionadas por políticas intervencio- nistas dos países do primeiro mundo e de instituições como a IPPF (International Planned Parenthood Federation), Fundação Ford e Rockefeller ${ }^{16}$ incentivando leis como a "Convenção sobre a Nacionalidade da Mulher Casada"17, sob o Decreto n. 64.126 de 1969, que garantiu às mulheres e às meninas casadas, a manutenção de sua nacionalidade de origem em detrimento da tutela total do marido sobre a vida da mulher evitando para muitas o tráfico legalizado de pessoas.

Neste mesmo período vigorava no país o Código de Menores de $1927^{18}$ que mencionava apenas crianças e adolescentes em situação irregular e destacava aqueles considerados "libertinos" (os que provocam obscenidades a outrem, prostituem-se ou valem-se da prostituição de outros), numa clara concepção de "culpabilização da vítima”. Em 1924, o Decreto $16.590^{19}$ proibiu o trabalho aos menores de 21 anos em estabelecimentos noturnos e de shows artísticos, uma forma de erradicar a prostituição infanto-juvenil na época.

Sob a égide do silêncio e da repressão, a educação em sexualidade (totalmente inexistente sob o prisma da intencionalidade) foi intimamente atrelada à questão da saúde e da higiene na Lei Federal no 2.312 de $1954^{20}$, que implantou "Normas Gerais sobre Defesa e Proteção da Saúde" e introduziu no currículo escolar a "Educação Sanitária e Higiene".

No contexto destes vinte anos, a pauta dos direitos humanos esteve voltada para outros focos que não a dos direitos sexuais e reprodutivos, sobretudo mantendo a invisibilidade da adolescência como fase própria nas legislações.

\section{De 1970 até 1979}

\section{- $\mathbf{a}$ adolescência com foco na rebeldia}

De natureza intergovernamental, a Conferência Sobre População e Desenvolvimento realizada em Bucareste, em 1974, enfatizou as políticas demográficas como parte integrante do desenvolvimento social e econômico, com vistas ao bem estar da comunidade e das gerações futuras, sem afetação dos valores humanos e das particulari-

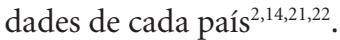

Foram reconhecidos o direito de casais e indivíduos a determinar o número de filhos, destacando o acesso a método contraceptivos e, principalmente, o papel do Estado na garantia desses direitos $^{4,21}$, a oferta de educação para ambos os sexos, a fixação da idade mínima para o primeiro casamento e o pleno consentimento dos indivíduos para isso ${ }^{22}$. Os países foram encorajados a diminuir a fecundidade entre as mulheres no 
início de sua idade reprodutiva, ou seja, na adolescência, desde que não interferissem nos seus interesses.

A paternidade responsável ganhou destaque como um objetivo a ser alcançado por meio de educação e como fator importante na redução do número de mulheres e meninas que arcam sozinhas com o sustento e a educação da família, diminuindo as possibilidades de investimento em si mesmas e na vida social através da educação e do trabalho ${ }^{22}$.

No Brasil, a adolescência continuava sendo vista para os que estavam em situação irregular ou eram objetos de medidas judiciais. No campo do ensino vigorava a Lei de Diretrizes e Bases da Educação 5.692/1971 ${ }^{23}$ com a introdução da figura da "orientação educacional", que dentre outras atribuições, na prática, trataria de informar sobre sexualidade. Somente em 1974 o Conselho Federal de Educação, através do Parecer 2.264/197424, legitima a educação em saúde e as primeiras abordagens da sexualidade na escola.

Em 1975, o Governo Federal lança o "Programa de Saúde Materno-Infantil - Diretrizes Gerais da Política de Saúde Materno-infantil"25 com ações voltadas à faixa etária de 5 até 19 anos, demonstrando nítida invisibilidade para a fase.

A Lei Federal 6.202/75 ${ }^{26}$ (que ainda vigora) atribuiu à gestante estudante a possibilidade de continuar os estudos em regime domiciliar após o oitavo mês e no período da licença-maternidade. Esta garantia é fundamental para as adolescentes que engravidam durante o processo de escolarização básica e o término dos estudos.

Em 1978 surge o "Programa de Prevenção da Gravidez de Alto Risco ${ }^{27}$ ” com atenção especial à gestação na adolescência. Hoje, postula-se que a gravidez na adolescência tenha maiores agravantes sociais que biológicos ${ }^{28}$.

Em 1979 um novo Código de Menores $^{29}$ (Lei Federal 6.697/79) é sancionado, mas no que e refere aos direitos sexuais e reprodutivos mantémse o observado no Código de 1927.

Assim, este período deixou subentendido nos documentos legais os direitos sexuais e reprodutivos da população adolescente, enquadrando-os ora dentro da infância, ora como adultos.

\section{De 1980 até 1989 \\ - respeito à adolescência como fase própria}

Na ONU e no Brasil o período foi de intensas mudanças. No que tange aos direitos sexuais e reprodutivos muitas conquistas foram alçadas nas Conferências e Encontros internacionais sobre a mulher. Foi em 1984, no "Encontro Internacional de Saúde da Mulher”, realizado na Holanda, que se tornou público o termo "direitos reprodutivos" e problematizou o termo "saúde da mulher" como escasso em muitos aspectos ${ }^{30}$.

Em 1985 houve a implantação do "Programa de Assistência Integral da Saúde da Mulher $(\text { PAISM })^{31}$, que advertiu para a necessidade de se implantar ações em saúde, que contemplassem mulheres adolescentes, sobre as DTS, a gravidez antes dos quinze anos e as causas de óbitos por motivos obstétricos, e enfatizou a importância de ações abrangentes que acompanhassem as mudanças de comportamento na sociedade.

No âmbito internacional, a Conferência sobre População e Desenvolvimento, realizada em 1984 no México $^{32}$, ratificou grande parte dos acordos estabelecidos anteriormente. Recomendou-se ênfase no planejamento familiar voluntário e enfoques diferenciados para a população jovem. Duas questões foram reforçadas - os direitos reprodutivos e o envolvimento dos jovens no processo de autonomia sobre sua sexualidade.

Em 1989 a Convenção dos Direitos da Criança garantiu direitos básicos de proteção ao desenvolvimento saudável e criou diretrizes para a proteção de questões mais específicas como a erradicação das desigualdades de gênero no campo da escolaridade ${ }^{33}$. Nessa Convenção, que no Brasil foi promulgada pelo Decreto 99.710 de 21/11/1990, criança é toda pessoa menor de dezoito anos, exceto quando a Lei Nacional determinar a maioridade mais cedo.

No Brasil, a década foi de envolvimento de entidades e movimentos sociais nas políticas públicas. O Conselho Federal de Medicina aprovou a resolução 1246/88 (arts. 103 ao 109) que garante a qualquer pessoa, inclusive ao menor de idade, o sigilo, a confiabilidade e a privacidade nos atendimentos ${ }^{26,34}$.

Em 1989, o "Programa de Saúde do Adolescente (PROSAD)" 35,36 surge num momento onde há altos índices de fecundidade e gravidez antes dos quinze anos. Este programa teve como objetivos a saúde integral do adolescente, a redução da morbimortalidade, o estímulo a estudos da adolescência, prevenção em DST/HIV/AIDS, contracepção e saúde materna, destacou o papel dos meninos na saúde reprodutiva e a prevenção e detecção precoce da violência sexual para ambos os sexos.

Essa década foi, sem dúvida, uma preparação para a vinda de políticas públicas mais direcionadas aos ideais de liberdade e autonomia de decisão. Para o segmento da adolescência represen- 
tou a conquista de um espaço na legislação com nome e peculiaridades a serem definidas.

\section{De 1990 até 1999}

- o adolescente como sujeito de direitos

A Conferência Internacional de Direitos Humanos de Viena (1993) ${ }^{37}$ recomendou aos países a eliminação de todas as formas de discriminação com base no sexo, destacando a importância do desenvolvimento harmonioso da personalidade de meninos e meninas, garantindo-lhes proteção plena e um ambiente familiar seguro.

O planejamento familiar foi novamente destacado como ato voluntário do casal e individual, e importantes considerações sobre violência sexual (mutilações genitais, exploração sexual infanto-juvenil, gravidez forçada em tempos de guerra, pornografia infantil, estupro) enfatizaram a juventude como segmento mais vulnerável a estes crimes.

A Conferência Internacional sobre População e Desenvolvimento realizado no Cairo- $1994^{38}$ trouxe, além do avanço teórico conceitual, as necessidades dos indivíduos em detrimento das metas demográficas. Os termos "saúde sexual e direitos reprodutivos" ganharam definição mais política.

A CIPD-94 $4^{38}$ condensa o consenso obtido e enfatiza a criação de programas de informação sobre orientação e serviços de saúde reprodutiva para homens e jovens, a paternidade responsável, o empoderamento das moças sobre sua vida sexual e reprodutiva, o envolvimento de diferentes organizações para atuar no esclarecimento dos adolescentes sobre a saúde sexual e reprodutiva, a eliminação de barreiras jurídicas, ideológicas e culturais no acesso dos adolescentes a informações seguras sobre gravidez e esterilizações indesejadas, maternidade precoce e DST. Indicou que os programas de orientação e informação em que há o envolvimento dos adolescentes são considerados os mais eficientes porque atendem diretamente suas necessidades em formas de abordagem e linguagem.

Cinco anos após a Conferência do Cairo, a ONU realizou uma avaliação e atualização das estratégias do seu Programa de Ação: a Conferência Internacional sobre População e Desenvolvimento - Cairo + 5-1999 $9^{39}$, mostrou que os avanços foram significativos e enfatizou a urgência na redução da mortalidade materna, na atenção aos adolescentes e sua saúde reprodutiva e HIV/ AIDS. Recomendou-se a participação dos jovens como protagonistas, indicou a inclusão de forma- ção em questões relativas à saúde sexual e reprodutiva, igualdade e equidade de gênero, conduta sexual responsável e prevenção de todas as formas de violência sexual. Incluiu-se a urgência na prevenção da gravidez precoce e mortalidade materna, e a criação de sistema de registro e indicadores com base no sexo e idade e que o matrimônio não seja impedimento para a vida social.

Os governos foram incentivados a criar iniciativas de prevenção, redução e tratamento para jovens e adolescentes com HIV/AIDS, eliminar barreiras jurídicas e sociais de acesso do adolescente às informações, serviços e insumos para sua saúde sexual e reprodutiva.

No Brasil, foi promulgada a Doutrina de Proteção Integral - Lei 8.069/1990 26,40 que estabelece o Estatuto da Criança e Adolescente. A lei protege contra qualquer forma de abuso e constrangimento sexual, garante prioridade de atendimento à adolescente gestante e fortalece demais legislações específicas de proteção à criança e ao adolescente.

A Portaria Interministerial no 796 de 29/05/1992 ${ }^{26}$, dos Ministérios da Educação e Saúde, estabeleceu normas de procedimentos educativos sobre a transmissão e a prevenção do vírus HIV. Determinou-se a proibição de exigências de teste sorológico para admissão de matrículas de alunos ou para a contratação de qualquer funcionário; a garantia de sigilo sobre sua sorologia e a proibição da distinção de classes especiais ou escolas específicas pelo critério sorológico. Por estar diretamente vinculada ao lócus escolar, protege muitos adolescentes e ainda os informa.

A Lei 9.263/1996 ${ }^{26}$ assegurou o planejando familiar como direito e liberdade de escolha. No que se refere à adolescência, somente restringe acesso aos métodos cirúrgicos, não tendo nenhuma outra implicação quanto à idade, às informações e aos métodos contraceptivos.

Em 1997, a resolução 256 do Conselho Nacional de Saúde implantou a notificação compulsória das mortes maternas, sendo posteriormente ampliada pela Portaria 653/2003 do Ministério da Saúde; Resolução do CFM 1.179/2005 e Portaria do MS 1.119/2008. Essa medida visava melhorar a qualidade de dados da vigilância epidemiológica de óbitos de mulheres em idade fértil (10 a 49 anos) e serviu para a percepção de que havia números altos de adolescentes registrados nos comitês de morte materna por baixo acompanhamento pré-natal, indicando aos governos a necessidade de políticas públicas direcionadas ${ }^{41}$.

No campo da educação, a Lei de Diretrizes e Bases da Educação Nacional 9.394/1996, instituiu 
novas bases programáticas curriculares. Os Parâmetros Curriculares Nacionais (1998) estabeleceram a "orientação sexual" como componente curricular a ser trabalhado como tema transversal e como forma de inclusão efetiva da educação em sexualidade nas escolas como direito ${ }^{42}$.

Em 1999, o Ministério da Saúde lança a "Norma Técnica de Prevenção e Tratamento dos Agravos Resultantes da Violência Sexual contra Mulheres e Adolescentes" visando a sensibilizar os profissionais envolvidos no atendimento das adolescentes vítimas de violência sexual a atuarem com práticas mais humanizadas, como estratégias de adesão, acolhimento e consolidação das abordagens na garantia e no restabelecimento da saúde dessas adolescentes ${ }^{43}$.

Nessa década, a visão de adolescência mudou radicalmente sob o olhar da lei. A Doutrina de Proteção Integral tirou a adolescência do campo da situação irregular e passou a considerar o segmento com um todo, implantando ações preventivas e protetivas. No campo dos direitos sexuais e reprodutivos, os avanços alçados abrangeram âmbitos importantes: notificar e mapear os óbitos maternos, planejar a família com liberdade e garantir a escola como um dos lócus de educação em sexualidade.

\section{De 2000 até 2010 \\ - o adolescente como protagonista}

Para a ONU ficou claro que o acúmulo de metas e programas de ações precisavam mais de implantações, revisões e comitês de acompanhamento. O resultado foi a Cúpula do Milênio no ano 2000, em que foram definidas oito "Metas de Desenvolvimento do Milênio" ${ }^{44}$.

No Brasil, a década foi rica em garantir juridicamente o status de protagonismo aos adolescentes. Em 2004, o "Pacto Nacional pela Redução da Morte Materna e Neonatal" indicou a necessidade de se estabelecer protocolos de atendimento e garantia de oferta de métodos anticoncepcionais, com atenção especial ao adolescente ${ }^{45}$.

No ano de 2005, o Programa "Saúde Integral de Adolescentes e Jovens"46 e o "Marco LegalSaúde: um direito do adolescente ${ }^{26 "}$ incorpora políticas de direitos sexuais e reprodutivos e educação em sexualidade.

A Portaria $\mathrm{n}^{\circ} 1.508$ de $2005^{47}$ alterou a Norma Técnica "Prevenção e Tratamento dos Agravos Resultantes da Violência Sexual contra Mulheres e Adolescentes" e considerou que menores de 18 anos, grávidas com direito ao aborto legal, devem ter a autorização de responsáveis ou tutores para a solicitação do procedimento, além de serem acolhidas e esclarecidas sobre seu direito de escolha. Já as menores de 14 anos, necessitam adicionalmente de comunicação ao Conselho Tutelar.

Nesse mesmo ano, a "Norma Técnica de Atenção Humanizada ao Abortamento ${ }^{48 "}$ reforçou os preceitos do consentimento e destacou o direito ao sigilo, respeito, confiabilidade, à informação, acolhimento e atendimento humanizado. Pela Lei Federal 11.108/2005 ${ }^{49}$, todas as parturientes (inclusive adolescentes) ganharam o direito à presença de acompanhante durante o trabalho de parto, parto e pós-parto imediato, no âmbito do Sistema Único de Saúde-SUS.

Mudanças no Estatuto da Criança e do Adolescente surgem para ampliar a compreensão de atendimento integral deste segmento no Sistema Único de Saúde através da Lei Federal $11.185 / 2005^{50}$.

No documento "Marco Teórico e Referencial: Saúde Sexual e Saúde Reprodutiva de Adolescentes e Jovens", produzido em 2006, o Ministério da Saúde apresentou propostas de diretrizes para atuação articulada nas ações relativas ao tema. No mesmo ano, a Resolução 1.811 do CFM (Conselho Federal de Medicina) estabeleceu normas éticas de utilização da Anticoncepção de Emergência, afirmando que ela pode ser utilizada em qualquer etapa da vida reprodutiva e fase do ciclo menstrual, como forma de prevenção da gravi$\mathrm{dez}^{26}$.

Em 2007, foi instituído pelo Decreto 6.286 o "Programa Saúde na Escola ${ }^{51 "}$ que tem como objetivo articular ações permanentes de educação e saúde para a melhoria da qualidade de vida da população, a promoção da saúde sexual e reprodutiva com ênfase em ações no combate às diversas formas de homofobia e da livre orientação sexual.

A Lei Federal 11.664/2008 ${ }^{52}$ estabeleceu a todas as mulheres que já tenham iniciado sua vida sexual, independentemente da idade, ações de saúde na prevenção, detecção, tratamento e seguimento dos cânceres do colo uterino e de mama, no âmbito do Sistema Único de Saúde SUS.

Em 2009, a Lei Federal $12.010^{53}$ alterou o Estatuto da Criança e do Adolescente em muitos aspectos. Adicionou ao poder público a obrigatoriedade de proporcionar assistência psicológica à gestante e à mãe, no período pré e pós-natal. A assistência deve ser também prestada a gestantes ou mães que manifestem interesse em entregar seus filhos para adoção.

A Lei 12.015/200954, conhecida como "Lei do Estupro de Vulnerável” alterou o Código Penal e 
aumentou todas as penas dos crimes que tenham como vítima menores de dezoito anos ou pessoas com deficiência mental; uma forma de se coibir a violência sexual contra crianças e adolescentes.

A nota técnica no 13/200926 do Programa Nacional - DST/AIDS recomendou a garantia irrestrita aos preservativos masculinos. Orienta o poder público a facilitar o acesso das populações mais vulneráveis aos preservativos masculinos, proibindo a vinculação de prescrição médica, solicitação de documentos de identificação, participação obrigatória dos usuários em palestras e outras reuniões.

Um importante manual técnico do Ministério da Saúde sobre adolescentes e jovens marca o fim da década. As "Diretrizes Nacionais para a Atenção Integral à Saúde de Adolescentes e Jovens na Promoção, Proteção e Recuperação da Saúde ${ }^{55}$ " trouxe como paradigma o enfoque do trabalho com adolescentes e jovens em temas estruturantes (participação juvenil, equidade de gêneros, direitos sexuais e direitos reprodutivos, projeto de vida, cultura de paz, ética e cidadania, igualdade racial e étnica), demonstrando que as políticas públicas devem transversalizar as áreas para obter melhores resultados. Este documento também aponta a capacidade de posicionamento dos jovens e adolescentes frente à vida e à sua saúde.

Assim, essa década conseguiu, em termos legais, definir uma linha de atuação com os adolescentes em que seu desenvolvimento integral está centrado no desenvolvimento das habilidades necessárias para alcançar sua autonomia e garantir direitos sexuais e reprodutivos. Acompanhou os preceitos propostos pela ONU e provocou uma mudança na cultura legal do país.

\section{Conclusão}

A adolescência, com suas peculiaridades e vulnerabilidades representa uma importante parcela da população em que as políticas públicas devem ser criteriosamente alçadas, pois impactos negativos ou positivos terão desdobramentos no futuro, podendo comprometer um longo período de tempo e grande parte da humanidade.

A atuação da ONU e do Brasil em consolidar um conceito amplo de direitos reprodutivos e saúde sexual, não tem sido em vão. Os esforços vêm sendo alcançados gradativamente, acompanhados pela sociedade civil através do controle social, ampliados e aprofundados com o auxilio da ciência, das mudanças culturais e de novas conjunturas econômicas e sociais, e tem substancialmente provocado impactos positivos no mundo.

No entanto, ainda prevalecem maiores conquistas na área dos direitos reprodutivos. Tanto no Brasil como na ONU o avanço da saúde sexual para direitos sexuais ainda engatinha.

\section{Colaboradores}

SP Moraes e MSS Vitalle participaram da concepção, pesquisa e escrita do artigo. 


\section{Referências}

1. Reis RR. Os direitos humanos e a política internacional. Rev. Sociol. Polit. 2006; 27:33-42.

2. Berquó E. O Brasil e as recomendações do Plano de Ação do Cairo. [acessado 2011 abr 4] Disponível em: http:// www.abep.nepo.unicamp.br/docs/outraspub/saudereprodutiva/SR_p23a35.pdf

3. Alves JED. Demografia, democracia e direitos humanos. Rio de Janeiro: IBGE; 2005. Texto para Discussão no 18.

4. Diaz M, Cabral F, Santos L. Os direitos sexuais e reprodutivos. In: Ribeiro C, Campus MTA, organizadores. Afinal, que paz queremos? Lavras: Editora UFLA; 2004. p. 45-70.

5. Alves JED. A Polêmica Malthus versus Condorcet reavaliada à luz da transição demográfica [dissertação]. Rio de Janeiro: Escola Nacional de Ciências Estatísticas; 2002.

6. Alvarenga AT, Schor N. Contracepção feminina e política pública no Brasil: pontos e contrapontos da proposta oficial. Saúde Soc. 1998; 7(1):87-110.

7. Tonelli MJF. Direitos sexuais e reprodutivos: algumas considerações para auxiliar a pensar o lugar da psicologia e sua produção teórica sobre a adolescência. Psicologia \& Sociedade 2004; 16(1):151-160.

8. Organização Mundial de Saúde (OMS). Saúde reprodutiva de adolescentes: uma estratégia para ação. Genebra: OMS, FNUAP, Unicef; 1989. [acessado $2010 \mathrm{fev}$ 11]. Disponível em: http://bvsms.saude.gov.br/bvs/publicacoes/cd03_11.pdf.

9. Taquette SR, Vilhena MM, Silva MM, Vale MP. Conflitos éticos no atendimento à saúde de adolescentes. Cad Saude Publica 2005; 21(6):1717-1725.

10. Gomes WA, Costa COM, Sobrinho CLN, Santos CAST, Bacelar EB. Nível de informação sobre adolescência, puberdade e sexualidade entre adolescentes. J Pediatr 2002; 78(4):301-308.

11. Brêtas JRS, Ohara CVS, Jardim DP, Aguiar Junior W, Oliveira JR. Aspectos da sexualidade na adolescência. Cien Saude Colet 2011; 16(7):3221-3228.

12. Comision Económica para América Latina y el Caribe (Cepal). [site]. [acessado $2013 \mathrm{dez} 17$ ]. Disponível em: http://www.eclac.cl/cumbres/getProd.asp?xml=/cumbres/7/37/P37.xml\&xsl=/cumbres/phistoriaf.xsl

13. Biblioteca Virtual de Direitos Humanos da USP. Proclamação de Teerã-1968. [acessado 2011 dez 12]. Disponível em: http://www.direitoshumanos.usp.br/index. php/Confer\%C3\%AAncias-de-C \%C3\%BApula-das$\mathrm{Na} \% \mathrm{C} 3 \%$ A7\%C3\%B5es-Unidas-sobre-Direitos-Humanos/proclamacao-de-teera.html

14. Correa S, Januzzi PM, Alves JED. Direitos e saúde sexual e reprodutiva: marco teórico-conceitual e sistema de indicadores. [acessado 2011 abr 04]. Disponível em: http:// www.abep.org.br/fotos/Dir_Sau_Rep.pdf

15. Organização das Nações Unidas (ONU). [site]. [acessado 2013 dez 17]. Disponível em: http://www.un.org. br/es/development

16. Pegorer MAS. A construção histórica dos direitos sexuais e reprodutivos da mulher. Brasil. [acessado 2012 ago 30]. [cerca de 21 p.]. Disponível em: http://aads.org.br/arquivos/HistoricoDSR.pdf

17. Senado Federal. Direitos Humanos - Instrumentos internacionais e documentos diversos. Brasília: Senado Federal; 1996.
18. Brasil. Decreto no 17.943 A, de 12 de outubro de 1927. Consolida as leis de Assistência e proteção a menores. Diário Oficial da União 1927; 31 dez.

19. Brasil. Decreto no 16.590, de 10 de setembro de 1924. Aprova o regulamento das casas de diversão pública. Diário Oficial da União 1924; 13 set.

20. Brasil. Lei Federal no 2.312, de 3 de setembro de 1954. Normas Gerais sobre Defesa e Proteção da Saúde. Diário Oficial da União 1954; 4 set.

21. Plano de Acção Mundial sobre a População. [editorial]. [acessado $2011 \mathrm{dez}$ 12]. Disponível em: http://analisesocial.ics.ul.pt/documentos/1223913276E6kTI9ln9Gk32JJ2.pdf

22. Nazareth JM. Análise crítica do Plano de Acção Mundial sobre População. [internet]. [acessado 2011 nov 13]. Disponível em: http://analisesocial.ics.ul.pt/documentos/1223913202W2mPX4gx0Lz97GC5.pdf

23. Brasil. Lei Federal 5.692; de 11 de agosto de 1971. Fixa diretrizes e Bases para o Ensino de $1^{\circ}$. e $2^{\circ}$ graus e dá outras providências. Diário Oficial da União 1971; 12 ago.

24. Silva IO, Siqueira VHF, Rocha GWF. Educação Sexual e gravidez de adolescentes: significados construídos por docentes do curso de formação de professores em uma escola pública do Rio de Janeiro. Rev Electrónica de Enseñanza de las Ciencias 2009; 8(1):216-231.

25. Brasil. Anais da V Conferência Nacional de Saúde. [acessado 2012 nov 13]. Disponível em: http://bvsms.saude. gov.br/bvs/publicacoes/0212cns_anais1.pdf

26. Moraes SP, Vitalle MSS. Direitos sexuais e reprodutivos na adolescência. Rev Assoc Med Bras 2012; 58(1):48-52.

27. Nagahama EEI, Santiago SM. A institucionalização médica do parto no Brasil. Cien Saude Colet 2005; 10(3):651-657.

28. Vitalle MSS, Amâncio OMS. Gravidez na Adolescência. Promotoria de Justiça de Presidente Prudente Infância e Juventude Pessoa com Deficiência, 2004 . [acessado 2012 nov 17] Disponível em: http://www.pjpp.sp.gov. br/2004/artigos/11.pdf

29. Brasil. Lei Federal no 6.697, de 10 de outubro de 1979. Institui o Código de Menores. Diário Oficial da União 1979; 11 out.

30. Mattar LD. Reconhecimento jurídico dos direitos sexuais: uma análise comparativa com os direitos reprodutivos. Sur, Rev. int. direitos human. 2008; 5(8):60-83.

31. Brasil. Ministério da Saúde (MS). PAISM - Programa de Assistência Integral a Saúde da Mulher. [acessado 2012 nov 17]. Disponível em: http://bvsms.saude.gov. br/bvs/publicacoes/assistencia_integral_saude_mulher .pdf

32. Population Information Program. Leis e politicas que afetam a fecundidade. [editorial]. [acessado $2011 \mathrm{dez}$ 12]. Disponível em: http://www.k4health.org/system/ files/048361POR.PDF

33. Brasil. Decreto 99.710, de 21 de novembro de 1990. Promulga a Convenção dos Direitos da Criança. Diário Oficial da União 1990; 22 nov.

34. Conselho Federal de Medicina. Resolução 1.246/1988. Código de Ética Médica. [acessado 2012 nov 17] Disponível em: http://www.portalmedico.org.br/resolucoes/ cfm/1988/1246_1988.htm 
35. Melo MCP, Coelho EAC. Integralidade e cuidado a grávidas adolescentes na Atenção Básica. Cien Saude Colet 2011; 16(5):2549-2558.

36. Brasil. Ministério da Saúde (MS). Secretaria Nacional de Programas Especiais de Saúde. Divisão Nacional de Saúde Materno-Infantil. Programa de Saúde do Adolescente: bases programáticas. Brasília: MS; 1989.

37. Biblioteca Virtual de Direitos Humanos da USP. Declaração e Programa de Ação de Viena-1993. [acessado $2011 \mathrm{dez}$ 12]. Disponível em http://www.direitoshumanos.usp.br/index.php/Sistema-Global.-Declara\%C3\%A7\%C3\%B5es-e-Tratados-Internacionais-de -Prote\%C3\%A7\%C3\%A3o/declaracao-e-programade-acao-de-viena.html

38. Relatório da Conferência Internacional sobre População e Desenvolvimento. Plataforma de Cairo, 1994. [acessado 2011 mar 11]. Disponível em: http: //200.130.7.5/spmu/portal_pr/eventos_internacionais/ onu/Relat\%C3\%B3rio\%20Cairo.pdf.

39. Organização das Nações Unidas (ONU). Medidas clave para seguir ejecutando El Programa de Acción de La Conferencia Internacional sobre Población y El Desarrolo. [acessado $2011 \mathrm{dez} 17]$. Disponível em: http://www. unfpa.org/webdav/site/global/shared/documents/ publications/1999/key_actions_sp.pdf

40. Brasil. Lei 8.069, de 13 de julho de 1990. Dispõe sobre o Estatuto da Criança e do Adolescente e dá outras providências. Diário Oficial da União 1990; 16 jul.

41. Brasil. Conselho Nacional de Saúde. Resolução 256, de 1 de outubro de 1997. Resolve definir o óbito Materno nos estados e municípios como evento de notificação compulsória para a Vigilância epidemiológica. Diário Oficial da União 1998; 12 fev.

42. Brasil. Lei Federal 9.394, de 20 de dezembro de 1996. Estabelece Diretrizes e Bases da Educação Nacional. Diário Oficial da União 1996; 23 dez.

43. Brasil. Ministério da Saúde (MS). Secretaria de Atenção Básica. Departamento de Ações Programáticas Estratégicas. Prevenção e Tratamento de Agravos resultantes de violência Sexual Contra Mulheres e adolescentes. [acessado $2011 \mathrm{dez}$ 13]. Disponível em: http://bvsms.saude. gov.br/bvs/publicacoes/prevencao_agravo_violencia_ sexual_mulheres_3ed.pdf

44. Fundo de Populações das Nações Unidas. A visão da CIPD: aonde nos levou essa jornada de 11 anos? Relatório de uma plenária do UNFPA realizada na XXV Conferência Internacional sobre População promovida pela IUSSP; Tours, França 19 de julho de 2005.

45. Brasil. Ministério da Saúde (MS). Secretaria de Atenção Básica. Departamento de Ações Programáticas Estratégicas. Pacto pela Redução da Mortalidade Materna e Neonatal. Brasília: MS; 2006.

46. Brasil. Ministério da Saúde (MS). Secretaria de Atenção à Saúde. Saúde integral de adolescentes e jovens: orientações para a organização de serviços de saúde. Brasília: Editora do Ministério da Saúde; 2005.

47. Brasil. Ministério da Saúde. Portaria 1.508, de 1 de setembro de 2005. Dispõe sobre o Procedimento de Justificação e Autorização da Interrupção da Gravidez nos casos previstos em lei, no âmbito do Sistema Único de Saúde-SUS. Diário Oficial da União 2005; 2 set.
48. Brasil. Ministério da Saúde (MS). Secretaria de Atenção à Saúde. Departamento de Ações Programáticas Estratégicas. Área Técnica de Saúde da Mulher. Atenção Humanizada ao Abortamento: norma técnica/Ministério da Saúde, Secretaria de Atenção à Saúde, Departamento de Ações Programáticas Estratégicas. Brasília: MS; 2005.

49. Brasil. Lei Federal 11.108, de 7 de abril de 2005. Altera a Lei $n^{\circ} 8.080$, de 19 de setembro de 1990, para garantir às parturientes o direito à presença de acompanhante durante o trabalho de parto, parto e pós-parto imediato, no âmbito do Sistema Único de Saúde - SUS. Diário Oficial da União 2005; 8 abr.

50. Brasil. Lei Federal 11.185 , de 5 de outubro de 2005. Altera o caput do art. 11 da Lei no -8.069 , de 13 de julho de 1990. Dispõe sobre o Estatuto da Criança e do Adolescente e dá outras providências. Diário Oficial da União 2005; 10 out.

51. Brasil. Decreto 6.826, de 5 de dezembro de 2007. Institui o Programa Saúde na Escola - PSE, e dá outras providências. Diário Oficial da União 2007; 6 dez.

52. Brasil. Lei Federal 11.664, de 29 de abril de 2008. Dispõe sobre a efetivação de ações de saúde que assegurem a prevenção, a detecção, o tratamento e o seguimento dos cânceres do colo uterino e de mama, no âmbito do Sistema Único de Saúde - SUS. Diário Oficial da União 2008; 30 abr.

53. Brasil. Lei Federal 12.010, de 3 de agosto de 2009. Dispõe sobre adoção; altera as Leis nos 8.069 , de 13 de julho de 1990 - Estatuto da Criança e do Adolescente, 8.560, de 29 de dezembro de 1992; revoga dispositivos da Lei no 10.406, de 10 de janeiro de 2002 - Código Civil, e da Consolidação das Leis do Trabalho - CLT, aprovada pelo Decreto-Lei no 5.452 , de 1ำ de maio de 1943; e dá outras providências. Diário Oficial da União 2009; 4 ago.

54. Brasil. Lei Federal 12.015, de 7 de agosto de 2009. Altera o Título VI da Parte Especial do Decreto-Lei no 2.848, de 7 de dezembro de 1940 - Código Penal, e o art. 1ํ da Lei no 8.072 , de 25 de julho de 1990, que dispõe sobre os crimes hediondos, nos termos do inciso XLIII do art. $5^{\circ}$ da Constituição Federal e revoga a Lei no 2.252 , de 1o de julho de 1954, que trata de corrupção de menores. Diário Oficial da União 2009; 10 ago.

55. Brasil. Ministério da Saúde (MS). Secretaria de Atenção em Saúde. Departamento de Ações Programáticas Estratégicas. Diretrizes nacionais para a atenção integral à saúde de adolescentes e jovens na promoção, proteção e recuperação da saúde. Brasília: MS; 2010.

Artigo apresentado em 02/04/2014

Aprovado em 24/11/2014

Versão final apresentada em 26/11/2014 